\title{
Study of Analysing and Processing of Big Data by Organizations in Indian Context
}

\author{
*Sidra Tariq, "Dr. Asif Ali Syed \\ *Research Scholar, ${ }^{\#}$ Associate Professor, Department of Business Administration, Faculty of \\ Management Studies and Research | Aligarh Muslim University, Aligarh, India. \\ *sidtariq25@gmail.com, "asifalisyed@yahoo.com
}

\begin{abstract}
Every business organization needs valuable data and insights for understanding audience intent and consumer's likings. Big data in this acts as a significant part as it supports in precede the needs of customers for which the data needs to be well presented and appropriately analyzed. Big Data permits organization to segregate customers in broad way which permits a business to hold consumers in a real-time, as in this tough competitive time you need to treat customers how they want. In simplified term "Big Data is a mix of processes and tools by which huge data grid through various form with each other and enormous amount of heterogeneous and rationalized information is created which in addition, used to figure out the utmost valuable customers. It also provide assistance for businesses to innovate, create and pitch new experiences, services, and products. The availability of such information creates opportunities for organizations. The paper here discusses about big data elements, its maintenance, handling and storage of varieties of big data by organizations and gains of big data analytics to organizations. The paper also analyze about the velocity of data generated and analysis of big data by organizations to understand its impact on organization working and consumer decision respectively. The paper also gives avenues for future research by explaining the application and practices of organization in the era of big data analytics.
\end{abstract}

Index Terms: Big data Analytics, Data Velocity, Big data processing, Data elements, Process factors.

\section{OBJECTIVES OF THE STUDY}

- To explain Big data processing, maintenance, handling and system in organizations elements.

- To study about the maintenance, handling, storage of big data by organizations.

- To analyze different varieties of Big Data used by organizations.

- To explain major Big data applications in Business.

\section{ReSEARCH Methodology}

The study is confined to Organizations analyzing and processing Big Data in Indian Context. In our survey, we use a convenience sampling as our sampling method and the sample presents the population characteristics. The respondents (sample in our study) were the employees working as the business/data analyst in various organizations dealing with data analytics in India. A total of 50 questionnaire were distributed for this research, and after doing the consistency inspection only 32 were the valid responses and 18 responses were found invalid and so were dropped out. The researcher collected data from 32 respondents (sample Size) using structured questionnaire with open and closed ended questions having different Industry type, company, job profile and location. The study was descriptive in nature and have cross sectional research Design. The Questionnaire was circulated to respondents by using Google Form and through E-mails. The data was collected online, analyzed using Microsoft Excel tool and then presented through different graphs. Our questionnaire employs a dichotomous scale for close ended questions, except for the demographic profile and open ended questions.

\section{INTRODUCTION}

"Big data analytics industry in India is estimated to be Rs 17,615 crore in revenues annually (FY18), growing at a rate of $33.5 \%$, Big data industry in India is expected to grow seven times in the next seven years, estimated to become a Rs 1,30,000 crore industry by 2025 and can create a lot of new growth opportunities", report of Rajnesh De on India Analyzes [1]. It has developed a new type of businesses, that analyze and aggregate industry data and started to build it aggressively, with huge information flow results in analyzing services and products, suppliers and buyers, consumer intent and preferences. 


\subsection{Big Data processing requirements}

"Data processing is a course of execution of specific operations on a set of database manually or automatically and involves transforming the data into useful outputs. It encompass comparisons, alternative actions and storing data for future use in the form of reports and documents which can be further used by organizations. Feedback collected is being moved to processing stages of the information system, this is a stage at which management can originate the most value from data through powerful processing tools. These processing activities turn a massive collection of facts into meaningful information that can then be used for informed decision making in business.

\subsection{Big Data elements:}

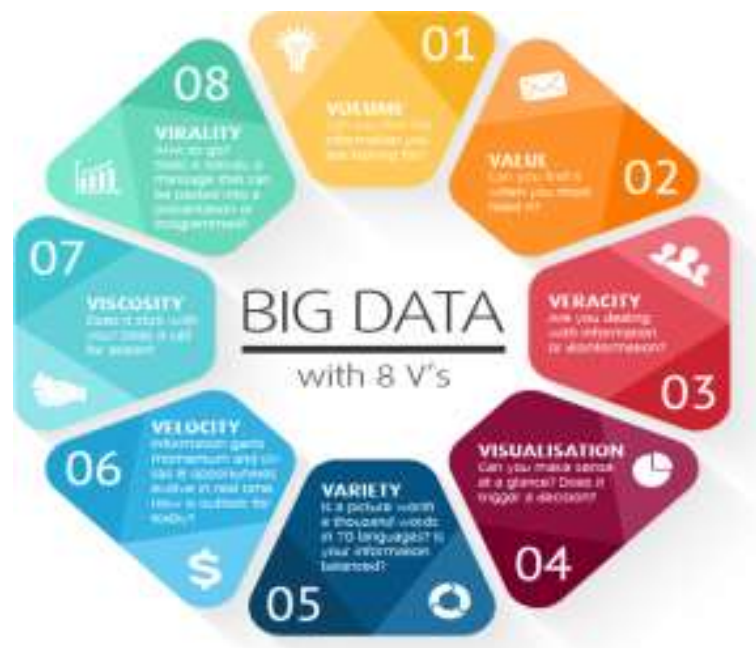

\subsection{Data-Driven Companies and how they perform}

We set out questions which analyze that how data-driven companies work and proved to be better performers. We shared structured questionnaire with executives associated with companies and ask them about processing and analyzing data with their organizational and technology management practices, and gathered data from them through their responses which was further analyzed. We found a broad spectrum of processing inputs and analysis inputs in every industry. It was analyzed, that the companies characterized themselves as data-driven performs better and give productive business outcomes and results. Data has a immense role in understanding important acumens about target demographics and customer preferences. After analyzing, data points explains about consumer behavior, traits, and life events. Companies can use such inputs for product enhancements, strategy building and marketing drives to attract the target customers. Big data along with technology added efficiency at which large sets of structured and unstructured data can be analyzed, it will be collected and examined to reveal unexpected insights. Big data alters how the minor companies do business and it is inspected through data collection and interpretation. Innovative and economical technologies are emerging which is making amazingly easy for the organizations to immaculately implement big data results.

\section{LiTERATURE REVIEW}

Erevelles [2] highlighted the fact that firms which do not deploy resources and technologies to use big data application will struggle to develop a sustainable competitive advantage.

Maniyka , Chui and Brown [3] defines big data as "datasets whose size is beyond the ability of typical database software tools to capture, store, manage, and analyze. The author further states that big data can provide more accurate and detailed performance data in real-time or near real-time, allowing managers to analyze performance variability, minimizing risks and finding new insights, improving decision making process and proposes five major contributions big data can make in general to businesses: transparency creation, performance improvement, population segmentation, decision making support, and innovative business models, products, and services.

Wamba [4] defines big data analytics as the holistic process that involve the collection, analysis, use and interpretation of data for gaining valuable insights, creating business value and establishing competitive advantages. The authors investigates that in a big data revolution, organizations are collecting more voluminous data than ever before for seeking smarter business strategies by leveraging meaningful insight from the data sets. They focused on three key dimensions which
Source:

https://www.sciencedirect.com/science/article/pii/B978012 $\underline{8054673000041}$ 
enhances firm performance .These include information quality, business value and user satisfaction. The information quality plays a vital role for increasing business and firm performance and has a positive influence on satisfaction, loyalty, trust in the IT framework and user and knowledgeable-sharing behavior. Business value is at the heart of what managers pursue from BDA framework and information quality plays a critical role in generating business value and user satisfaction.

Cheah and Wang [5] define big data as a valuable information asset and an opportunity to gain efficiency, productivity, revenue and profitability in business. They laid emphasis on developing a business model which they define as a process of how firm conducts its business, utilize resources, leverage its suppliers and partners to develop and deliver goods and services for creating and capturing value. Thus demonstrates a mechanism of developing a big data driven business model innovation from the market, strategic and economic perspective through value discovery, value creation and value realization aspects. This mechanism is a progressive and dynamic process. From the market perspective, companies can determine market demands of their products and services through big data analysis and can identify opportunities and discover value. At a strategic level, new business model can be developed using process, product, market and organizational innovation for creating value. And at the economic perspective, firm can realize value by lowering operational cost and finding new revenue streams by tapping on new markets using big data thus continuously refining their existing business model to gain competitive advantage.

Hofacker [6] demonstrated in their study as to how the study of consumer behavior can benefit from the presence of big data. In their work they highlighted that consumers have become an incessant generator of different types of data namely structured, transactional as well as unstructured behavior data. In today's data driven world, the main driver for decision making and executing marketing campaigns, emerges out from big data. Thus big data has yielded more than half of marketing initiatives especially insights into understanding consumer behavior. Using big data, companies can sense a gap between what consumers has experienced and what he or she wants, identify ideas for new product development and improvement, extract new product ideas from online communities, detecting problems using E- word-of-mouth.

Hartmann, [7] focuses on applying data driven business model (DDBM) framework to capture and creating value from big data in start-ups. They states that data deluge results from increased usage of internet, social media, mobile devices etc. They define data as the new oil, which guarantees growth and profit. The emergence of big data has led to the creation of entirely new business models for creating value.

With increased data deluge, Recommendation system help in reducing search cost, serve as important source of information to increase awareness set and reduced product uncertainty for consumers, Bergemann \& Ozmen, [8].

A report by Econsultancy and Monetate [9] highlighted that $94 \%$ of e-commerce sites consider recommendation systems to be critical competitive advantage to be implemented.

$\mathrm{Ku} \&$ Tai [10] in their study integrated the information processing model and social psychological forces with theory of reasoned action of Ajzen \& Fishbein [11] and recommendation system will influence consumer purchase behavior.

Chen [12] found that more recommendations improve sales and help in filtering personalized products from large catalogues of product to minimize the choices for consumer. Thus organizations can adopt recommendation system to improve sales and should manage reputation system to avoid fake and untruthful ratings or reviews.

Yang [13] addressed the influence of informational factors on purchase intention in social recommender systems in China by surveying 161 users who were using a famous social network site (WeChat).The results showed a positive link between information quality dimensions and consumer purchase intention. The author also emphasized the important mediating effects of trust and consumer perceived value between information quality factors and consumer purchase intention in social recommender systems.

Aggarwal \& Rahul [14] in their paper explicated a comprehensive model to explored the relationship between transaction security and payment system and perceived security, trust, satisfaction and purchase intentions among 500 Indian online consumers. The findings indicated that perceived security had positive effect on satisfaction and positive impact on trust and overall had a positive effect on consumer purchase intentions.

\section{Big DATA: APPLiCATIONS IN BUSINESS}

Applying and understanding big data is vital for corporations, which collects huge data from existing infrastructure that will give them chance to notice unseen acumens. Big data demonstrate an abundance of new prospects from understandings of customer interactions [15]. The broad business opportunities include: Mechanization, comprehensive insights, and faster \& improved decision making which is explained below:

\section{Mechanization}

Big data is capable to enhance internal efficiencies and operations by process automation. Enormous amount of real-time data is instantly analyzed and constructed into business processes for decision making. With accessible 
IT infrastructure and lowering cloud computing costs, automized data collection and storage is within reach.

\section{Comprehensive insights}

Hidden opportunities which were unknown to organizations are being discovered through review of huge sets of data, which is further be used to develop new products or improve existing ones and proved to be priceless in the present competitive landscape.

\section{Faster \& improved decision making}

With the advancement of data analytics technology, along with the ability to analyze new sources of data, businesses can now be able to analyze information instantly and make smart, informed decisions.

\section{DATA ANALYSIS \& INTERPRETATION}

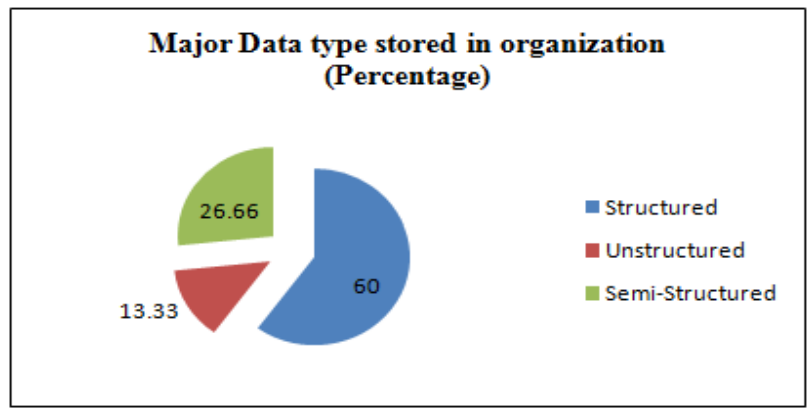

Graph 5.1: Major Data type stored in organizations

Interpretation: As per the responses collected from thirty different employees working with different firms, majority of data stored in structured form and rest in semi and unstructured form.

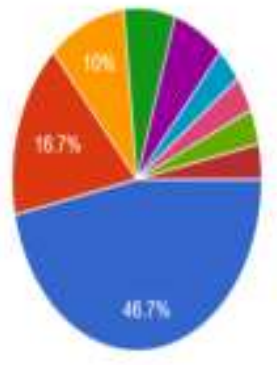

Graph 5.2: Data volume organizations currently monitors

Interpretation: As per the responses collected from thirty different employees working with different firms, data volume is stored in Petabytes.

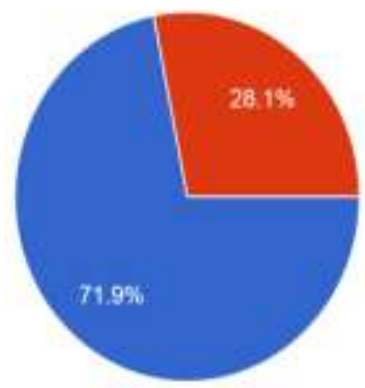

Interpretation: As per the responses collected from thirty different employees working with different firms, majority of data stored In - House.

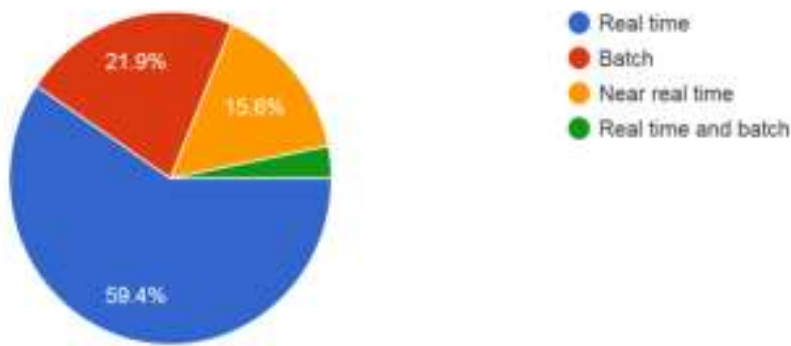

Graph 5.4: Velocity of data generated by Organizations

Interpretation: As per the responses collected from thirty different employees working with different firms, Velocity of Data generated is in Real Time.
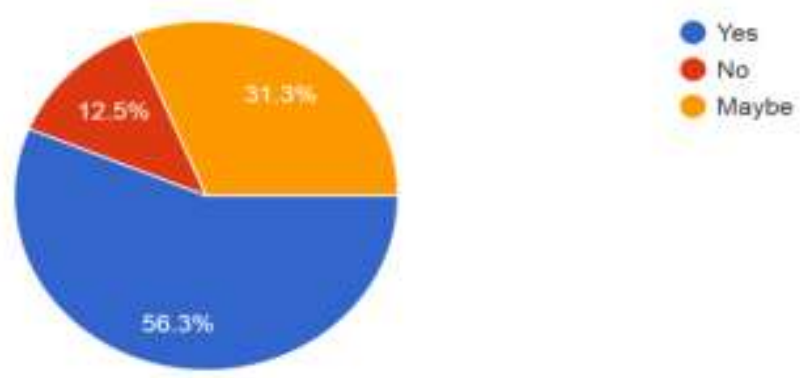

Graph 5.5: Impact of Velocity of data on Organization Working

Interpretation: As per the responses collected from thirty different employees working with different firms, Velocity of Data has major impact on Organization Working.

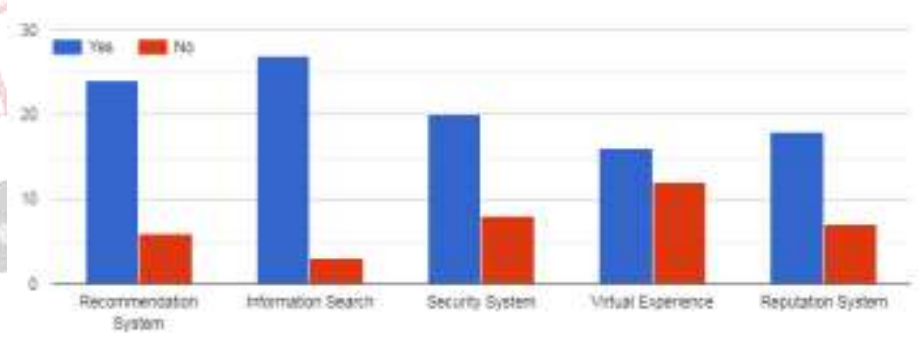

Graph 5.6: Organizations process factors

Interpretation: As per the responses collected from thirty different employees working with different firms, Big data analytics helping organization majorly in ascending order as developing Recommendation System, Information System, Security System, Virtual Experience, Reputation System respectively.

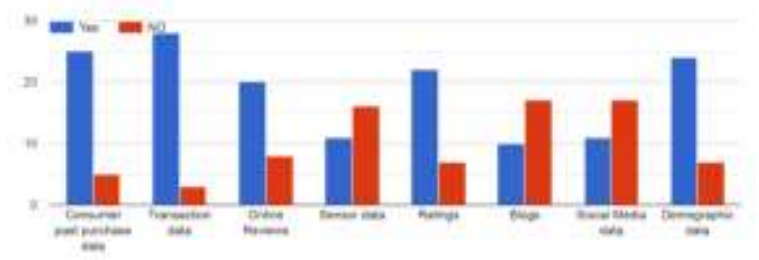

Graph 5.7: Percentage of different varieties of data organizations are currently analyzing

Graph 5.3: Storage of data by Organizations 
Interpretation: As per the responses collected from thirty different employees working with different firms, percentage of different varieties of data organizations currently analyzing which are in the sequence of transaction data, Consumer past purchase data, demographic data, Ratings, Online reviews, Social media, Sensor data and Blogs respectively.

\section{FINDINGS OF THE STUDY}

$>$ Majority of data stored by the organizations are in structured form and rest in semi and unstructured form.

$>$ Data volume is huge which is stored in Petabytes in organizations.

$>$ The Velocity of Data generated by organizations is in Real Time.

$>$ Majority of data stored In - House by the organizations.

$>$ It is been find out that Velocity of Data has major impact on Organization Working.

$>$ It has been find out that Big data analytics helping organization majorly in ascending order in developing Recommendation System, Information System, Security System, Virtual Experience, Reputation System respectively.

$>$ Varieties of data organizations currently analyzing which are in the sequence of transaction data, Consumer past purchase data, demographic data, Ratings, Online reviews, Social media, Sensor data and Blogs respectively.

\section{CONCLUSION}

From the study and the data gathered and interpretation we can conclude that, majority of data stored by the organizations are in structured form and rest in semi and unstructured form and the Data volume is huge which is in Petabytes with real time Velocity which has a major impact on organization working. As majority of data stored In - House by the organizations and analyzed, it has been find out that Big data analytics helping organization majorly in ascending order in developing Recommendation System, Information System, Security System, Virtual Experience, Reputation System respectively. Varieties of data organizations currently analyzing which are in the sequence of transaction data, Consumer past purchase data, demographic data, Ratings, Online reviews, Social media, Sensor data and Blogs respectively.

Database is gathered from employees business customer names and addresses maintained by a company for use in its own marketing strategies. Big Data with technology input draw more interest with due course of time. Across the world organizations are promisingly formulating plans and paths to benefit from developments in the field of big data analytics. The existing frameworks which have been developed in some countries have proved to be vital to analyze and identify uncertain issues. We anticipate much action in the business domain in the years to come. Expanding the learnings from recent usage of big data analytics, and identifying the outcomes along with strategies compilations initiatives by organizations, we can witness huge potential that big data holds in India. We also studied about the processing system and important elements of Big data platform and technology.

\section{REFERENCES}

[1]. India Analyzes Big: Data Science and Analytics Market in India| AUTHOR: RAJNEESH DE - NOVEMBER 23, 2018.

[2]. Erevelles, S., Fukawa, N., \& Swayne, L. (2016)."Big Data consumer analytics and the transformation of marketing". Journal of Business Research, 69(2), 897-904.

[3]. Manyika J., Chui M., Brown B., Bughin J., Dobbs R., Roxburgh C., (2011). "Big data: The next frontier for innovation, competition, and productivity", Mckinsey and Company.

[4]. Wamba et al.,(2018). "Turning information quality into firm performance in the big data economy", Management Decision, http://doi.org/10.1108/MD-04-2018-0394

[5]. Cheah, S and Wang, S., (2017)."Big data-driven business model innovation by traditional industries in the Chinese economy", Journal of Chinese Economy and Foreign Trade Studies, http://doi.org/10.1108.JCETS-05-2017-0013

[6]. Hofacker, C.F., Malthouse, E.C., Sultan, F. (2016)."Big data and consumer behavior: imminent opportunities", Journal of Consumer Marketing, Vol. 33 No. 2, pp.89-97.

[7]. Hartmann, P.M. et al., (2016)."Capturing value from big data - a taxonomy of data-driven business models used by start-up firms", International Journal of Operations \& Production Management, Vol. 36 Iss. 10

[8]. Bergemann, D and Ozmen, D (2006).”Optimal pricing with recommender systems". In Proceedings of the 7th ACM conference on Electronic commerce,43-51.

[9]. E-consultancy and Monetate (2013).’The Realities of Online Personalization". Technical report, E-consultancy and Monetate.

[10]. Ku, Y.C. and Tai, Y.M. (2013), "What happens when recommendation system meets reputation system? the impact of recommendation information on purchase intention", Proceedings of the Annual Hawaii International Conference on System Sciences, pp. 1376-1383.

[11]. Ajzen, I., and M. Fishbein,(1980)."Understanding Attitudes and Predicting Social Behavior", Prentice-Hall, New Jersey.

[12]. Chen, P.Y., Wu, S.Y., and Yoon, J.(2004).”The impact of online recommendations and consumer feedback on sales". ICIS 2004 Proceedings, page 58

[13]. Yang, X. (2018). "Influence of informational factors on purchase intention in social recommender systems", Online Information Review, https://doi.org/10.1108/OIR-12-2016-0360

[14]. Aggarwal, A \& Rahul, M. (2018)."The effect of perceived security on consumer Purchase intentions in electronic commerce", Int. J. Public Sector Performance Management, Vol. 4, No. 1.

[15]. Wang, J (2003)." Data Mining: Opportunities and Challenges". Hershey, PA: Idea Group Publishing. 